\title{
A arte da fuga: Os mecanismos da liquidez
}

The Art of Fugue: The Mechanisms of Liquidity

L'art de la fugue: les mécanismes de la liquidité

José Maria Castro Caldas

\section{(2) OpenEdition}

\section{Journals}

Edição electrónica

URL: http://journals.openedition.org/rccs/617

DOI: $10.4000 /$ rccs. 617

ISSN: 2182-7435

\section{Editora}

Centro de Estudos Sociais da Universidade de Coimbra

Edição impressa

Data de publição: 1 Setembro 2008

Paginação: 31-52

ISSN: 0254-1106

Refêrencia eletrónica

José Maria Castro Caldas, "A arte da fuga: Os mecanismos da liquidez », Revista Crítica de Ciências Sociais [Online], 82 | 2008, colocado online no dia 01 outubro 2012, criado a 19 abril 2019. URL : http:// journals.openedition.org/rccs/617; DOI : 10.4000/rccs.617 


\title{
JOSÉ MARIA CASTRO CALDAS
}

\section{A arte da fuga: Os mecanismos da liquidez'}

\begin{abstract}
A ideia de "liquidez" enquanto característica da fase actual da modernidade, presente na obra mais recente de Zygmunt Bauman, convida a uma leitura cruzada entre este autor e Keynes. Quer em Bauman, quer em Keynes, a liquidez aplica-se a relações que podem ser facilmente revertidas, ou revertidas a baixo custo, e a sistemas que, sendo caracterizados pela precariedade dos laços que unem os seus elementos constituintes, tendem a ser, eles próprios, instáveis e precários. Em ambos os autores, a liquidez e a especulação surgem como respostas racionais à incerteza e, ao mesmo tempo, como estratégias individuais que contribuem para o aumento do risco sistémico. As duas abordagens são complementares e coerentes. A leitura cruzada sugere a existência de mecanismos da liquidez transversais a diferentes domínios institucionais cuja identificação é aqui ensaiada.
\end{abstract}

\section{Introdução}

A presença da palavra keynesiana liquidez no título de um livro de Zygmunt Bauman - A modernidade líquida - é mais do que uma mera coincidência. Em Bauman, a liquidez é evocada para dar conta de uma sociedade que, dada a fraca resistência à "separação dos átomos" (Bauman, 2000: 2), tem dificuldade em conservar a sua forma. Em Keynes, refere-se a uma propriedade dos mercados financeiros - a facilidade com que os agentes podem desfazer-se dos seus activos e adquirir outros que os substituam. No entanto, quer em Bauman, quer em Keynes, a liquidez aplica-se a relações que podem ser facilmente revertidas, ou revertidas a baixo custo, e a sistemas que, sendo caracterizados pela precariedade dos laços que unem os seus elementos constituintes, tendem a ser, eles próprios, instáveis e precários. Para ambos, a liquidez é a metáfora mais adequada à "fase actual, em muitos sentidos nova, da história da modernidade" (Bauman, 2000: 2).

\footnotetext{
${ }^{1} \mathrm{O}$ autor agradece a leitura atenta, os comentários críticos e as correcções a uma versão anterior deste ensaio de José Reis, João Rodrigues, Luís Francisco Carvalho, Ana Santos e Margarida Moz.
} 
À primeira vista, o paralelismo não nos leva além destas constatações. As duas análises situam-se em planos diferentes. Enquanto Bauman aborda as diferentes manifestações da "separação dos átomos" tendo por referência a totalidade social e a totalidade da experiência existencial, Keynes, mais modestamente, trata das estratégias individuais e das consequências sistémicas dessas estratégias num domínio institucional preciso: os mercados monetários e financeiros.

Acontece, no entanto, que as duas abordagens são complementares e coerentes. A liquidez dos mercados financeiros analisada por Keynes é a manifestação de um processo generalizado num domínio particular que, para Bauman (2000: 121), é a principal fonte de incerteza e a origem de processos que tendem a alastrar, generalizando-se. Além disso, a leitura cruzada sugere que a liquidez se manifesta de forma semelhante em diferentes espaços da vida social e pessoal - uma semelhança que sugere a existência de mecanismos da liquidez transversais.

O exercício aqui proposto consiste, não numa leitura crítica de Bauman e de Keynes, mas numa interpretação articulada de ambos, orientada para a investigação de hipotéticos mecanismos da liquidez transversais a diversos domínios institucionais. Nas páginas que se seguem, apresentam-se, em primeiro lugar, as teses de Bauman e de Keynes, ou pelo menos interpretações já decorrentes do exercício de leitura cruzada. Estas interpretações sustentam o exercício de identificação dos mecanismos da liquidez que é ensaiado na quarta secção. A discussão das tendências que decorrem dos mecanismos hipoteticamente descritos é deixada para as notas conclusivas.

\section{A liquidez de Bauman}

A liquidez, enquanto metáfora da sociedade comercial, está longe de ter sido descoberta por Bauman. Isto mesmo é por ele reconhecido quando evoca a referência à "fusão dos sólidos" contida no Manifesto Comunista. É relevante recordar a este respeito que, no Manifesto, a "fusão dos sólidos" dizia respeito ao "impiedoso" derrube por parte da burguesia "de todas as relações feudais, patriarcais e idílicas" que não deixaria qualquer "nexus entre pessoas senão o descarado interesse próprio e o empedernido pagamento a contado" (Marx e Engels, 1848: 3), o que, remetendo obviamente para Thomas Carlyle e o seu cash nexus, mostrava que, pelo menos num ponto - o horror à imposição da relação comercial como única forma de relacionamento entre pessoas -, as críticas de Marx e as dos críticos românticos do capitalismo, ou, na linguagem do Manifesto, "socialistas feudais", coincidiam. O acordo, evidentemente, terminava aí - enquanto o romântico "socialismo feudal", "meio lamentação, meio libelo, meio eco 
do passado, meio ameaça do futuro" (Marx e Engels, 1848: 15), apesar de "incisivo" na sua crítica, advogava um regresso às relações patriarcais, Marx e Engels aspiravam à emancipação e anteviam-na no futuro.

Compreende-se assim que Hirschman, na sua discussão acerca de interpretações rivais da sociedade de mercado (Hirschman, 1982), incluísse Marx e os críticos românticos do capitalismo numa mesma categoria ("teses de autodestruição"), que englobava todas as perspectivas que sustentam que "a sociedade capitalista [...] exibe uma pronunciada tendência para socavar a fundação moral em que qualquer sociedade, incluindo a variedade capitalista, deve assentar" (Hirschman, 1982: 1466). Hirschman fazia, no entanto, notar que Marx se limitara a assinalar a corrosão dos valores tradicionais na sociedade burguesa, nunca desenvolvendo um raciocínio de implosão do capitalismo pela liquefacção das suas fundações morais. Para Hirschman, os casos paradigmáticos da "tese da autodestruição" eram Schumpeter, Horkheimer e Hirsch. Hoje, vinte e cinco anos passados, Hirschman consideraria possivelmente também a inclusão de Bauman nesta categoria.

\subsection{As duas fases da grande transformação}

Dada a longa linhagem da liquidez como metáfora da sociedade de mercado, é de certa forma surpreendente que ela surja agora em Bauman associada apenas ao "estádio actual da modernidade" (Bauman, 2000: 2).

Reconhecendo que a "fusão dos sólidos" é uma característica permanente da modernidade, Bauman sustenta porém que a "grande transformação" teria ocorrido em duas fases. Na primeira, os "sólidos" eram os padrões de dependência e de interacção pré-modernos; estes sólidos foram quebrados, mas logo substituídos por outros tão rígidos como os anteriores. Os indivíduos foram arrancados às suas pertenças e dependências tradicionais, mas logo embutidos em "molduras que [...] encapsulavam a totalidade das condições e expectativas de vida e determinavam o leque de projectos de vida e estratégias realistas" (Bauman, 2000: 7): as classes sociais, a diferença sexual ou a fábrica fordista. $\mathrm{Na}$ segunda fase, isto é, hoje, são estes novos "sólidos" o que está a ser liquefeito, à medida que os padrões de dependência e de interacção se tornam maleáveis a um ponto que nunca havia sido experimentado nem seria imaginável para as gerações passadas, e sem que nada de palpável e duradouro surja a substituí-los:

Hoje em dia os padrões e as configurações deixaram de ser "dados", e muito menos "evidentes"; existem simplesmente em demasia, colidindo uns com os outros [...] de tal modo que cada um deles perde grande parte dos seus poderes de compulsão e de coerção. (Bauman, 2000: 7) 
Olhemos então um pouco mais em detalhe para cada uma das fases da grande transformação, tal como são apresentadas de forma condensada em Bauman (2001). No princípio, a modernidade surge sob a forma de liberdade - e o princípio, na história da modernidade de Bauman, é o momento em que Deus aparece ao homem da Renascença, neste caso a Pico della Mirandola, anunciando-lhe que, ao contrário das outras criaturas que "têm uma natureza por mim prescrita [...] tu podes determinar os teus limites de acordo com a tua própria vontade" (Bauman, 2001: 21). Esta é a face emancipatória da modernidade.

O "acto constitutivo do capitalismo moderno", relembra-nos Bauman por outras palavras, envolveu a cisão da velha economia baseada na produção de valores de uso para satisfação de necessidades domésticas ou comunitárias, desenraizando nesse processo, por um lado, os negócios e, por outro, o trabalho:

[E]ste duplo acto libertou as acções orientadas para o lucro, assim como as orientadas para a subsistência, da rede de obrigações morais, emocionais e de vizinhança - mas, ao mesmo tempo, esvaziou essas acções dos significados que anteriormente veiculavam. (Bauman, 2001: 29)

Para o empreendedor, "a separação do negócio da esfera doméstica representou uma emancipação genuína. As suas mãos haviam sido desatadas, o céu era o único limite que a sua ambição não ousava transpor" (Bauman, 2001:30). Mas, para os trabalhadores arrancados às comunidades de origem e atirados para a oficina industrial, a separação transformava o trabalho de uma actividade dotada de um propósito, num mero exercício de esforço desprovido de dignidade. Para os artífices e os camponeses do passado,

o significado de "trabalho bem feito" deixara de ser claro [...]. Obedecer à rotina sem alma da oficina industrial, vigiado não por companheiros ou vizinhos mas apenas pelos sempre desconfiados [...] capatazes, obedecer a movimentos ditados por máquinas sem oportunidade para admirar o produto do próprio esforço e, muito menos, para se deter a julgar a sua qualidade, fazia do esforço uma futilidade. (Bauman, 2001:30)

E, na medida em que os seres humanos resistiam à futilidade do esforço, e essa resistência era interpretada como indolência - a aversão ao trabalho dos manuais de economia -, o trabalho parecia só poder ser obtido pela coerção, combinada em doses convenientes com a exortação moralista indutora de consentimento. O duplo movimento de separação revelava, 
assim, a outra face da modernidade: "O arranjo moderno - capitalista da coabitação humana tinha uma face de Janus; uma face emancipatória; a outra coerciva; cada uma delas voltada para uma secção diferente da sociedade" (Bauman, 2001: 26).

Na primeira fase da "grande transformação", conclui Bauman (2001: 30), “o capitalismo moderno [...] 'fundiu os sólidos'; [...] mas a fusão não era um fim em si mesmo: os sólidos foram liquefeitos de forma a que novos sólidos, mais sólidos do que os que haviam sido fundidos, pudessem ser moldados".

Mas a modernidade, ao mesmo tempo que amarrava os subordinados ao chão fabril em que podiam ser facilmente vigiados, obrigava também os vigilantes a permanecer nas torres de vigia, criando assim uma situação de dependência mútua. Unidos no Panopticon, para o pior e para o melhor, os seus habitantes sabiam que ele era simultaneamente um palco de conflito e uma mesa de negociação. A gestão, nesse enquadramento, era um exercício que balanceava entre a imposição coerciva de rotinas e as tentativas de recrear in vitro um novo "sentido de comunidade". A fábrica fordista, escreve Bauman (2001:37), que "procurava sintetizar ambas as tendências", era paradigmática de uma outra faceta desta etapa da modernidade: a ideia de que a ordem na produção e na sociedade tem de ser gerida.

A segunda etapa da "grande transformação" começa, nos termos de Bauman tomados de Marx, no momento em que o dono dos instrumentos descobre que não é obrigado a dirigir a orquestra: "Logo que puderam, os empreendedores capitalistas depositaram as tarefas de gestão nas mãos de servidores contratados" (Bauman, 2001: 39).

Mas este foi apenas um passo intermédio, correspondente a um episódico "capitalismo gestionário". O momento de os gestores repetirem o acto de desengajamento haveria de chegar em breve, inaugurando agora sim os "tempos de alta velocidade e aceleração, encurtamento dos prazos de compromisso, de flexibilidade, 'downsizing' e 'outsourcing'; [...] os tempos de ficar juntos 'até nova ordem' e enquanto 'a satisfação durar' (nunca mais)” (Bauman, 2001: 41), em suma a modernidade líquida.

Na modernidade pós-panóptica - a modernidade líquida -, a arte da fuga tornou-se na técnica principal de consolidação do poder. A desregulação é procurada porque os poderosos não querem ser regulados - "para o poder ser livre no seu fluxo, o mundo deve ser libertado de barreiras e controlos de fronteira" (Bauman, 2000: 14) -, mas também porque já não precisam de regular ninguém. Agora, a obediência é obtida com a simples ameaça de desengajamento, ou fuga (exit): "Entre a incerteza e a insegurança, a disciplina (ou antes, a submissão à condição 'não há alternativa') alimenta-se a 
si mesma, auto-reproduz-se" (Bauman, 2001: 42), tornando supérfluas as fábricas de obediência, os dispendiosos Panopticons.

O desmantelamento dos Panopticons é experimentado pelos indivíduos (e mesmo por Bauman) com perplexidade. Por um lado, o regime panóptico era cruel e desumano, e nesse sentido o seu desaparecimento pode ser representado como uma libertação. Mas, por outro lado, tinha também "algumas vantagens para as vítimas - trazia-lhes benefícios que mal se notavam na altura e que só recentemente se tornaram salientes com o seu desaparecimento" (Bauman, 2001: 42): proporcionava um enquadramento fiável em que era possível inscrever as esperanças e os projectos de um futuro melhor e conferia sentido à luta por melhores condições de existência no seu quadro.

\subsection{Individualização na modernidade líquida}

A forma que a modernidade assume no presente - a modernidade líquida distingue-se da anterior e caracteriza-se, segundo Bauman (2000: 29), não só pelo colapso da crença num "telos da mudança histórica [...], algum tipo de boa sociedade, sociedade justa e livre de conflitos", como pela "desregulação e privatização das tarefas e deveres da modernização", isto é, pela mudança de significado da individualização.

$\mathrm{Na}$ modernidade líquida, a individualização deixou de ser concebida como uma emancipação dos laços de dependência comunal. Na ausência de um quadro normativo claro e fiável, a identidade deixou de ser um "dado" para se transformar numa "tarefa" por que os actores, agora também autores, são responsabilizados: "a determinação heteronómica do estatuto social é substituída por uma autodeterminação obrigatória” (Bauman, 2000: 32).

No entanto, as tarefas da construção da identidade não são levadas a cabo por todos em pé de igualdade. Enquanto para alguns, poucos, os dois pólos da individualização - liberdade e segurança - se reforçam mutuamente (a liberdade de movimentos é mesmo um garante do poder e da segurança), para outros, a maioria, a liberdade é oferecida apenas em troca da segurança e experimentada como "incerteza, negras premonições e medo do futuro" (Bauman, 2001: 22). Todos são advertidos de que a perspectiva de sobrevivência, melhoramento e dignidade depende exclusivamente de si, e todos são pessoalmente responsabilizados em caso de fracasso. Mas, na medida em que só alguns dispõem dos recursos necessários para adquirir segurança pela liberdade, a modernidade líquida opera, na realidade, uma repartição desigual dos riscos. Para a maioria, a autonomia de jure não se traduz numa autonomia de facto, ou dito de outra forma, ao reforço da liberdade negativa não corresponde um reforço da liberdade positiva. 
Independentemente das circunstâncias individuais, a construção privada da identidade é sempre uma tarefa a ser levada a cabo num contexto de incerteza. Quando os "códigos e as regras" não são "evidentes em si mesmos", deixando de prescrever obrigações claras e bem definidas (Bauman, 2000: 7), quando "o estatuto de todas as normas [...] foi [...] severamente abalado, tornando-se frágil" (Bauman, 2000: 79), a construção da identidade tende a transformar-se "numa perpétua angústia de indecisão" (Bauman, 2000: 20), resultante da incerteza quanto à definição dos próprios fins e quanto às intenções e acções dos outros.

\subsection{A incerteza, a liquidez e as suas manifestações}

Num ambiente de incerteza, num "mundo desprovido de significados estáveis", a liquidez - isto é, a substituição do "engajamento e do compromisso [...] pelas técnicas da fuga” (Bauman, 2000: 108, 109) - surge como uma resposta racional dos indivíduos: "Escolha racional' na era da instantaneidade significa procurar a satisfação evitando as consequências e, particularmente, as responsabilidades que essas consequências implicam” (Bauman, 2000: 128).

A liquidez manifesta-se numa perda de significado dos compromissos pessoais, ou compromissos com um "plano de vida". O mundo "em que o futuro, na melhor das hipóteses, surge ténue e coberto pela névoa, mas, mais provavelmente, coberto de riscos e perigos" (Bauman, 2000: 163) torna pouco atractivo o estabelecimento de objectivos distantes. A liquidez envolve assim uma modificação do tempo - a perda de significado do longo prazo com a sua descretização numa sequência de momentos.

Para aqueles para quem a "dominação consiste na capacidade de fuga" (Bauman, 2000: 120), a instantaneidade tornou-se num ideal de referência. Bill Gates, conforme as observações de Sennett referidas por Bauman, fazia depender o sucesso da capacidade de "posicionamento numa rede de possibilidades, alternativa à paralisação numa actividade particular”. Isto implica que se evite "desenvolver laços (particularmente laços sentimentais) ou compromissos duradouros com o que quer que seja, inclusive com as próprias criações":

[Bill Gates] não tinha medo de enveredar por um caminho errado porque nenhuma escolha o obrigava a prosseguir na mesma direcção e porque voltar atrás ou virar para o lado continuavam a ser sempre opções imediatamente disponíveis. (Bauman, 2000: 124)

Para o "capital capaz de viajar rapidamente e com leveza" (Bauman, 2000: 121) a compressão do tempo é uma fonte de liberdade $e$ segurança. 
Para os outros é apenas de liberdade, ou melhor, de liberdade de escolha de objectos de consumo. Para estes, a actividade de consumo é a forma privilegiada de "fuga da angústia chamada incerteza" (Bauman, 2000: 81). Os objectos expostos nas prateleiras dos supermercados são então os únicos que se apresentam "completos com a promessa de certeza" de satisfação imediata (Bauman, 2000: 81). A vida do consumidor é uma sequência de momentos de gratificação.

A liquidez envolve também uma alteração de significado dos compromissos inter-pessoais. $\mathrm{O}$ mundo em que o futuro é difuso torna pouco aconselhável "a renúncia ao interesse próprio com vista a aumentar o poder do grupo" (Bauman, 2000: 163): "Segurar com demasiada força, sobrecarregar os nossos laços com compromissos vinculativos mútuos, pode ser francamente prejudicial se as oportunidades surgirem noutro sítio" (Bauman, 13: 2000).

Aqueles para quem a liberdade e a segurança são servidas em pacote dispensam facilmente os compromissos - a sua segurança pressupõe a flexibilidade. Outros poderão desejar a estabilidade ou sentir falta dela. Mas, na medida em que a oferta de segurança escasseia, a melhor alternativa consiste sempre em procurar imitar os primeiros. A consequência é a

decomposição dos laços humanos, das comunidades e das parcerias. Compromissos do tipo "até que a morte nos separe" tornam-se contratos "enquanto a satisfação durar”, temporários e transitórios por definição, por intenção e por impacto pragmático - e, portanto, com tendência a serem quebrados unilateralmente quando uma das partes pressente mais oportunidades e mais valor na opção de abandono da parceria, do que na tentativa de a salvar a qualquer custo incalculável. (Bauman, 2000: 163)

No processo, o que é modificado é o significado das relações interpessoais: "os laços e as parcerias tendem a ser tratados como coisas destinadas a ser consumidas, não produzidas; sujeitas ao critério de avaliação de todos os objectos de consumo" (Bauman, 2000: 163).

\subsection{A construção social e a instabilidade da identidade}

Contrariamente ao que poderia imaginar-se, a construção da identidade na modernidade líquida não deixou de ser um processo social. O que mudou foram os mecanismos desse processo. $\mathrm{Na}$ ausência do Big Brother invisível da primeira modernidade, capaz de absolutizar os valores e de prescrever os objectivos que devem ser prosseguidos, a questão dos valores foi também ela privatizada, transferida para os indivíduos. À incerteza de meios 
veio agora acrescentar-se um novo tipo de incerteza - uma incerteza de fins que consiste em determinar, "frente aos riscos conhecidos ou meramente adivinhados, quais dos múltiplos [...] fins 'ao nosso alcance' [...] se apresentam como prioritários” (Bauman, 2000: 61).

Os indivíduos, se bem que separados, não deliberam sobre os fins de costas voltadas uns para os outros. Observam-se mutuamente, de forma atenta e ansiosa, na expectativa de encontrar não só provas de que não são eles os únicos a viver as angústias da incerteza, mas também "exemplos" - sinais de fins que valha a pena perseguir. Os outros, em contrapartida, oferecem-se como objectos de consumo em "teatros em que os dramas privados são encenados, exibidos publicamente e publicamente observados" (Bauman, 2000: 70), ou como 'consultores' no mercado de exemplos.

Ser objecto de "desejo e admiração" (Bauman, 2000: 67) é a condição de sucesso e de autoridade de um consultor no mercado de exemplos e prova da importância dos valores por ele promovidos. No entanto, o vínculo causal entre a vontade de seguir um exemplo e a autoridade da pessoa exemplar não é claro: "A autoridade expande as fileiras de seguidores, mas, num mundo de incerteza e de fins cronicamente indeterminados, o número de seguidores é o que origina - o que é - a autoridade" (Bauman, 2000: 67).

O valor dos exemplos é necessariamente precário: "Os exemplos e as receitas são atractivos enquanto não são testados” (Bauman, 2000: 72). Uma vez que não existe exemplo capaz de cumprir as suas promessas de satisfação duradoura, as receitas da "vida boa" tendem a tornar-se obsoletas mesmo antes de passar o seu prazo de validade. Para os indivíduos, a tentativa de reduzir a incerteza de fins através da observação de exemplos tende a degenerar de consumo em vício e, como todos os vícios, "destrói a possibilidade de alguma vez dar origem à satisfação” (Bauman, 2000: 72) - quanto mais praticada e mais frustrações origina, mais se torna necessária, para ainda mais frustrações originar. Na sociedade, o valor dos exemplos é efémero - os exemplares transitam entre a fama e o esquecimento ao sabor de ventos e marés imprevisíveis e incontroláveis.

\subsection{A mercadorização dos compromissos e a instabilidade das relações inter- pessoais}

A mudança de significado dos compromissos interpessoais decorrente da mercadorização dos laços sociais, isto é, da sua submissão ao cash nexus, acarreta como consequência a desresponsabilização pelo destino das relações. Quando a relação é concebida como uma aquisição no mercado, a sua continuidade passa a estar condicionada apenas pelo teste da satisfação. 
Procurar contribuir activamente, com sacrifício se necessário, para a sua manutenção, faz tanto sentido quanto o esforço para gostar de um produto que revela não corresponder à expectativa. $\mathrm{Na}$ relação, como no caso do produto decepcionante, o que é natural é optar pela devolução, sempre que possível, e pela busca de alternativas. Em consequência, a precariedade das relações tende a transformar-se numa profecia auto-realizada:

Se o laço humano, como todos os objectos de consumo, não for algo a ser trabalhado com esforço continuado e sacrifício ocasional, mas antes algo de que se espera satisfação imediata, instantânea, no momento da compra - e algo que se rejeita quando não satisfaz [...] - então não faz sentido "gastar bom dinheiro num mau produto" [...] e muito menos sofrer desconforto e incómodo para salvar uma parceria. (Bauman, 2000: 164)

\subsection{Incerteza, liquidez e insegurança}

A incerteza, que, para a maioria dos indivíduos, se traduz em insegurança e ansiedade, desencadeando como resposta racional a procura de liquidez, tende a produzir instabilidade e insegurança sistémica agravada. Das consequências envolvidas nesta tendência, Bauman destaca a fragmentação social.

A modernidade líquida é um tempo de "secessão" em que os mais capacitados para a prática da arte da fuga procuram e conseguem desvincular-se dos seus compromissos e responsabilidades. Mas, na medida em que a "secessão" agrega os fugitivos com outros fugitivos semelhantes, o processo dá origem a "bolhas", espaços de protecção - comunidades só de nome, seladas do exterior e unidas apenas pela percepção de uma ameaça externa. O resultado é a 'guetização' - um processo de “confinamento espacial e de fechamento social” (Bauman, 2001: 117) que se auto-alimenta.

A canalização das emoções geradas pela incerteza existencial para uma frenética busca de "segurança-na-comunidade" produz o efeito de todas as profecias autorealizadas: uma vez desencadeada, tende a substanciar as suas motivações originais e a produzir continuamente "boas razões" e justificações para a acção original. (Bauman, 2001: 118)

Quando o exterior se apresenta como cada vez mais ameaçador, os "guetos voluntários", aqueles em que se entrou pensando ser sempre possível deles sair, passam a assemelhar-se a verdadeiros guetos. A sociedade fragmentada pode então tornar-se verdadeiramente perigosa - um terreno fértil para a expansão do mercado da lei e da ordem. 
Mas a sociedade fragmentada que, segundo Bauman, resultaria da liquefacção é também uma sociedade em que se dissolveram as "forças que podiam manter as questões da ordem e do sistema na agenda política" e os "laços que vinculam as escolhas individuais em projectos colectivos" (Bauman, 2000: 6):

O tipo de incerteza, de medo, e as negras premonições que assombram os homens e as mulheres no ambiente social fluido, em permanente mudança, com regras que mudam no meio do jogo sem aviso ou padrão discernível, não unem as suas vítimas. Os sofrimentos que causam aos indivíduos não são aditivos, não se acumulam num tipo de "causa comum" que pudesse ser prosseguida de forma mais eficaz juntando forças e agindo em uníssono. (Bauman, 2001: 48)

A liquidez de Bauman é um processo cumulativo. É uma armadilha, uma distopia capaz de substituir os pesadelos de Orwell e de Huxley.

\section{A liquidez de Keynes}

A liquidez de Keynes tem origem na separação da propriedade e do controlo e é, simultaneamente, condição dessa separação, ocorrendo pela primeira vez, como em Bauman, no momento em que o dono da orquestra descobre que não tem de ser necessariamente maestro.

Houve um tempo, lembra Keynes no início do famoso Capítulo 12 da Teoria Geral, em que as empresas "eram geralmente controladas pelos que empreenderam o investimento" e "o investimento dependia de uma oferta suficiente de indivíduos com temperamento determinado e impulsos construtivos que embarcavam nos negócios como forma de vida" (Keynes, 1936: 150), em que as decisões de investimento eram irrevogáveis, "indissolúveis, como o casamento" (Keynes, 1936: 160). Neste tempo, o investimento "produtivo" era sólido (ou fixo).

Com a criação e o desenvolvimento dos "mercados de investimento" esse tempo terminou. Os "mercados de investimento", caracterizados pela liquidez, operam diariamente uma reavaliação do investimento - algo que não fazia sentido no contexto anterior, caracterizado pela indissolubilidade dos laços do investidor com os seus activos - e, ao mesmo tempo que reavaliam, dão aos indivíduos "oportunidade para reverem os seus compromissos" (Keynes, 1936: 151), isto é, para se desfazerem dos seus activos, adquirindo ou não outros oferecidos no mercado. Estes mercados parecem ser uma fantástica inovação institucional que reúne o melhor de dois mundos: o rendimento que os tesouros não podem prometer e a liquidez que se pensava ser um atributo dos tesouros. 


\subsection{A ambiguidade da liquidez}

No entanto, para Keynes, a liquidez era ambígua, envolvendo o que ele próprio encarava como um dilema: "muitas vezes facilita, embora algumas vezes entrave, o curso do novo investimento" (Keynes, 1936: 160).

A razão pela qual a liquidez pode facilitar o investimento torna-se clara a partir do momento em que é reconhecida a "extrema precariedade da base de conhecimento" (Keynes, 1936: 149) em que se fundamentam as expectativas de rendimento futuro dos vários tipos de activos. Em contexto de incerteza, a liquidez é a saída de emergência que o investidor necessita de saber que existe para que ouse entrar num túnel mal iluminado de que não vê sequer o fundo. É a escapatória em caso de emergência: "Para o investidor individual, poder gabar-se da 'liquidez' do seu compromisso é algo que acalma os nervos e reforça a disposição para correr um risco" (Keynes, 1936: 149). É certo, no entanto, como lembrava Keynes, que as decisões de investimento são revogáveis para o indivíduo, mas não o são para a comunidade - uma não correspondência micro-macro que pode traduzir-se numa redução do risco individual não transponível para o agregado.

Mais complexa é a razão pela qual a liquidez pode entravar o curso do novo investimento. Os "mercados de investimento" foram instituídos no pressuposto de que iriam facilitar a realização do milagre da mão invisível: afectar o capital aos usos socialmente mais vantajosos. Segundo Keynes, as coisas passam-se bem ao contrário. Imaginemos, por absurdo que seja, que um agente omnisciente considerava vantajoso investir uma soma elevada construindo uma nova empresa. Será que continuaria disposto a fazê-lo se existisse no "mercado de investimento" um negócio equivalente, mas mais barato? Nesse caso, o novo investimento seria abandonado em troca da aquisição de títulos de propriedade de um negócio já existente; a avaliação do mercado (líquido) entravava o novo investimento. Mas por que motivo haveria o mercado de avaliar o investimento abaixo do seu valor fundamental, isto é, aquele valor que só o agente omnisciente conhece?

O mercado pode "enganar-se", tende mesmo a "enganar-se" sistematicamente, porque não existem agentes omniscientes, ou pelo menos um agente que seja tomado como tal pelos restantes, e porque as escolhas individuais feitas em contexto de incerteza não são independentes.

O valor dos activos tem uma natureza convencional, isto é, resulta de uma multiplicidade de decisões descentralizadas, mas não independentes. A consciência de que o valor dos activos resulta de uma multiplicidade de decisões justifica que cada indivíduo tenha em consideração na sua decisão 
a expectativa relativamente à escolha dos outros. $\mathrm{Na}$ realidade, os seus ganhos e perdas dependem da sua capacidade de prever as escolhas dos outros. E, na medida que as decisões de cada um dos outros são também condicionadas por expectativas do mesmo tipo, trata-se de adivinhar o que os outros pensam que irão ser as escolhas dos outros. Nos "mercados de investimento", como escrevia Keynes, não se trata apenas de prever quais os títulos que vão valorizar-se, nem quais os títulos que os outros pensam que vão valorizar-se, trata-se antes, num terceiro grau de recursividade, de "prever o que a opinião média dos peritos prevê como opinião média", podendo mesmo haver quem "pratique o quarto, o quinto e ainda mais elevados graus" de recursividade (Keynes, 1936: 156).

Keynes designava por especulação esta actividade de previsão de segundo, terceiro ou de grau ainda mais elevado, comparando-a a um jogo e opondo-a à empresarialidade, isto é, à "actividade de prever os rendimentos esperados dos activos ao longo de todo o seu ciclo de vida" (Keynes, 1936: 158) - o que hoje se designa por valor fundamental dos activos.

No mundo da liquidez financeira, a especulação pode ser considerada - dependendo de uma redefinição de racionalidade - uma modalidade de comportamento racional (Orléan, 1999; Rodrigues, 2007). A especulação, escrevia Keynes (1936: 155):

não é o resultado de uma propensão irracional (wrong-headed). É a consequência inevitável de um mercado de investimento organizado no modo acima descrito. Não é sensato pagar 25 por um investimento de que se antevê um rendimento que justificaria um valor de 30 , se ao mesmo tempo se acredita que o mercado irá valorizá-lo a 20 daqui a três meses.

Neste mercado, irracional seria basear as decisões de investimento no conhecimento que se dispõe acerca da rendibilidade do negócio a que se refere o activo bolsista:

O investimento baseado em expectativas genuínas de longo prazo genuínas é hoje [...] dificilmente praticável. Quem o tentar fazer, enfrentará não só mais dificuldades, como correrá riscos maiores do que alguém que se dedique a adivinhar melhor do que a multidão o modo como a multidão se vai comportar. (Keynes, 1936: 157)

\subsection{Auto-referencialidade da especulação e instabilidade}

Melhor do que no tempo de Keynes, compreendemos hoje que sistemas como o dos mercados financeiros podem comportar-se de forma complexa, se não mesmo caótica. Nestes mercados, como explica Orléan 
(1999: 59), "a opinião do mercado é, ao mesmo tempo, o objecto, aquilo que cada um tenta antever, e o produto - o que emerge das opiniões individuais quando cada um dos indivíduos está voltado para a descoberta da opinião maioritária".

Designando esta dinâmica de auto-referencial, Orléan mostra que, em certas circunstâncias, os grupos auto-referenciais "conseguem estabilizar-se através da produção endógena de uma crença reconhecida por todos" (Orléan, 1999: 60) - uma convenção - e mostra, ao mesmo tempo, que estas convenções, sob o ataque de especuladores que procuram vantagens “jogando" contra elas, podem entrar em colapso.

\subsection{A armadilha da liquidez e a necessidade de regulação heteronómica}

A liquidez, que, nos mercados financeiros, se apresenta como resposta racional à incerteza, tende a originar instabilidade sistémica, acrescentando incerteza à incerteza individual. Neste contexto, o que para Keynes surgia como extraordinário é que ainda houvesse, apesar de tudo, lugar para a empresarialidade. Se a empresarialidade tivesse fundamento racional, se dependesse do simples cálculo - da "média ponderada de benefícios quantificados por probabilidades quantificadas" - há muito teria "murchado e morrido" (Keynes, 1936: 161-162). Se ainda existe, é porque, na realidade, depende mais do optimismo espontâneo, dos animal spirits - "um impulso espontâneo para a acção” - do que do cálculo matemático.

Mas como o optimismo espontâneo que permite agir apesar da incerteza é, como qualquer estado psicológico, inconstante, a "vida económica do mundo moderno" estaria necessariamente sujeita a "crises de confiança" (Keynes, 1936: 161). Em contextos de crise de confiança, quando o medo paralisa os animal spirits, divididos entre consumo, investimento e liquidez, os agentes tenderiam a escolher o mais líquido dos activos - a moeda.

Podemos agora formular o dilema de Keynes de outro modo: os mercados contêm o pânico nos dois sentidos da palavra conter (Dupuis, 1992). A liquidez "acalma os nervos" e encoraja a formação de capital e, ao mesmo tempo, gera instabilidade e "crises de confiança" cujo resultado é uma corrida desordenada para a saída de emergência.

Para Keynes, como é sabido, o laissez faire não sobreviveria a comoções com estas proporções. Para ele, a ordem e a reprodução da sociedade de mercado dependiam de um centro de racionalidade exterior a ela própria: "Espero ver o Estado, que está em posição de calcular a eficiência marginal dos bens de capital no longo prazo com base na vantagem geral da sociedade, assumir uma responsabilidade cada vez maior na direcção do investimento" (Keynes, 1936: 164). 


\section{Os mecanismos da liquidez}

A leitura cruzada de Bauman e Keynes sugere, como acima ficou escrito, a existência de mecanismos da liquidez transversais a diversos domínios institucionais. A consideração desta hipótese envolve uma generalização de diferentes conceitos-chave, presentes na abordagem à liquidez de ambos os autores, nomeadamente: incerteza, expectativas, racionalidade, irracionalidade, empresarialidade, especulação, convenções, normas, instabilidade das convenções e armadilha da liquidez. A argumentação nesta secção é construída a partir do agrupamento de conceitos e da sua discussão sequencial.

\subsection{Incerteza e expectativas}

A incerteza, concebida de forma informal e abrangente como um estado mental de dúvida sobre o curso de acção a empreender - uma situação em que o actor "não sabe o que fazer" (Beckert, 1996) -, embora possa ser mais saliente nuns casos do que noutros, é, evidentemente, uma condição frequente nos assuntos correntes da vida.

Isto aplica-se à incerteza de tipo keynesiano. Este tipo de incerteza que se manifesta com particular acuidade nos mercados financeiros e monetários, pode estar presente em todas as situações em que as consequências das acções se projectam num futuro longínquo, sem que exista uma base de conhecimento que permita formular expectativas probabilísticas.

Mas a incerteza keynesiana - incerteza quanto aos melhores meios para alcançar fins claros, decorrente de falta de conhecimento -, a incerteza epistémica de meios, não é a única forma de incerteza nem a única incerteza relevante. Bauman falava de uma incerteza de fins, uma incerteza axiológica, que se referia ao estado mental de dúvida acerca dos fins que merecem ser prosseguidos. Sugeria também, um terceiro tipo de incerteza - uma incerteza deôntica, respeitante aos deveres e obrigações - que envolve a dúvida na relação do indivíduo com as normas.

O reconhecimento destas três formas de incerteza envolve naturalmente uma ontologia do actor que não é a da ortodoxia económica. Pressupõe um actor que reconhece as normas enquanto tal, isto é, enquanto regras que prescrevem obrigações e cuja obrigatoriedade não é refém de um juízo baseado numa deliberação custo-benefício. Pressupõe, ainda, um actor capaz de reflectir acerca das próprias preferências e de escolher os fins que prossegue - um actor autónomo, limitadamente autónomo, no sentido em que, no processo de formação das suas crenças, depende não só dele próprio, mas também dos outros (quer no processo de socialização, quer no contexto situacional). 
A acção em contexto de incerteza é sempre baseada em expectativas que, tal como as formas de incerteza, podem ser epistémicas, axiológicas e deônticas. Os mecanismos transversais da liquidez envolvem estes três tipos de incerteza e de expectativas.

\subsection{Racionalidade e irracionalidade}

O reconhecimento da incerteza não probabilizável conduz a uma reconceptualização da racionalidade. O agente de Keynes não dispõe pura e simplesmente dos recursos cognitivos que lhe permitam escolher racionalmente (nos termos prescritos pela teoria da decisão racional). Ele só pode ser racional se a racionalidade for concebida de forma abrangente como escolha justificada. A racionalidade relevante no quadro dos mecanismos transversais da liquidez refere-se a processos de deliberação que incidem em paralelo sobre fins (sujeitos a reconfiguração) e meios (dados e descobertos).

Irracional nesta perspectiva é a desadequação meios-fins - a escolha de fins que não podem ser efectivados com os meios disponíveis, ou de meios que não permitem efectivar os fins escolhidos.

\subsection{Empresarialidade e especulação}

O empresário nos termos de Keynes é o investidor que "dirige a sua mente para as perspectivas de longo prazo e só para essas” (Keynes, 1936: 160), baseando as suas decisões em estimativas do valor fundamental dos activos. A empresarialidade pode ser generalizada e integrada nos mecanismos transversais da liquidez como uma atitude de empenho ou compromisso com um projecto de vida ou uma relação inter-pessoal. $\mathrm{O}$ compromisso envolve a responsabilidade - a consciência de que o destino do projecto ou da relação depende pelo menos em parte de um contributo pessoal e uma disposição contributiva acompanhada de tradução prática - e uma crença no valor fundamental do projecto ou da relação, isto é, no seu valor intrínseco, não-convencional.

A liquidez é um estado de não-compromisso, quer com planos de vida, quer com os outros. A preferência pela liquidez é uma resposta racional à incerteza, qualquer tipo de incerteza, que, quando generalizada, tende a substituir a empresarialidade pela especulação.

A especulação, que nos mercados financeiros é a actividade que consiste em prever a valorização convencional dos activos, quando generalizada, transforma-se na escolha de fins orientada por "exemplos" com autoridade, referida por Bauman, ou no condicionamento das obrigações normativas à previsão do grau de conformidade dos outros a essas mesmas obrigações. A especulação traduz-se, em suma, em deliberação e acção orientada por valorizações convencionais. 


\subsection{Convenções e normas}

As convenções que em Keynes se referem quer a procedimentos de formação de expectativas, quer às expectativas propriamente ditas, quer a valorizações de activos, podem ser generalizadas como crenças intersubjectivas que emergem da interacção entre os agentes, que não se baseiam em nenhum valor fundamental exterior ao jogo auto-referencial das crenças e que são subjectivamente reconhecidas como tal. Por oposição, as normas são crenças intersubjectivas que radicam em valores fundamentais e são reconhecidas como tal pelos agentes, podendo motivar a acção independentemente de qualquer avaliação de custo-benefício.

A referência das normas a valores fundamentais não é garantia de uma adesão automática dos agentes (por isso mesmo existem normalmente sanções em caso de incumprimento), já que, na relação com as normas, existe sempre espaço para a justificação do incumprimento, em consequência do conflito com outras normas, da interpretação e da expectativa quanto à adesão dos outros. O último aspecto é particularmente importante, no sentido em que sugere que as normas estão também sujeitas a processos auto-referenciais com impacto nas expectativas deônticas, embora a exterioridade do valor fundamental relativamente ao jogo auto-referencial lhes possa conferir uma maior estabilidade.

Por outro lado, o facto de as convenções não radicarem em valores fundamentais também não exclui a possibilidade de se constituírem em fundamento de crenças e expectativas estáveis. Algumas convenções adquirem uma estabilidade que vai ao ponto de resistirem mesmo quando há fortes razões para serem abandonadas.

\subsection{Instabilidade das convenções}

No limite, a modernidade líquida de Bauman, como os mercados financeiros de Keynes, são sistemas sociais desprovidos de valores fundamentais não porque estes valores não existam, mas precisamente por existirem em conflito uns contra os outros. A ordem nestes sistemas assenta em convenções. Keynes e os seus herdeiros caracterizaram a dinâmica auto-referencial das convenções nos mercados financeiros. O jogo especular de Bauman a respeito da incerteza axiológica ilustra-a bem no domínio dos fins. Algo semelhante pode ocorrer com as obrigações. Na medida em que, para o agente limitadamente autónomo, a disposição normativa é condicionada pela expectativa de cumprimento dos outros, isto é, envolve a expectativa de reciprocidade (Gintis et al., 2005), as expectativas deônticas estão também sujeitas ao já familiar processo auto-referencial: a minha disposição depende da disposição de outros cuja disposição depende por sua vez... 
As convenções são arbitrárias - não se baseiam em qualquer valor fundamental. Mas se elas, apesar de arbitrárias, fossem sempre estáveis, como no caso de alguns dos equilíbrios dos "modelos de massa crítica" de Schelling (1978), não haveria fundamento racional para a procura de liquidez. Os agentes formulariam as suas expectativas com base em convenções que se transformariam em profecias auto-realizadas.

A liquidez é procurada porque não é possível confiar na estabilidade das convenções. Reconhecido que ficou acima que em algumas circunstâncias as convenções são estáveis, a questão fundamental é compreender as razões pelas quais podem não o ser.

As convenções são estáveis quando a generalidade dos agentes não tem razões para as abandonar ou quando, apesar de existirem boas razões, o abandono implica custos insuportáveis para o agente que o empreenda isoladamente (Runde, 1991). Num país em que os automobilistas conduzem pela esquerda, qualquer agente teria vantagens em guiar pela direita no caso de congestionamento da via convencional; no entanto, o risco dessa escolha é suficiente para dissuadir a generalidade dos condutores. Mesmo nos mercados financeiros, é possível encontrar exemplos. Keynes sugere um deles: dado que a desaprovação é mais provável quando se erra contra a convenção do que quando se erra com ela, um operador assalariado terá tendência para seguir a convenção mesmo quando está persuadido de que com isso pode estar a prescindir de um ganho.

Quando existem boas razões para abandonar a convenção e isso não envolve um custo proibitivo, existe um potencial para a convenção se tornar instável. Entre as boas razões, podem-se contar: o desvio da convenção relativamente ao que actor toma como valor fundamental; o incentivo decorrente de oportunidades de ganho em "jogadas" contra-convencionais, à maneira dos grandes especuladores bolsistas; ou a divulgação de nova informação.

O último aspecto, sublinhado por Keynes, é particularmente importante. No mundo do não-compromisso, a mente foca-se em tudo menos naquilo cujas vantagens só podem ser realizadas no longo prazo; tende, em particular, a concentrar-se em factos correntes, cuja importância pode resultar, não da relevância dos factos em si, mas da importância que o agente acredita ser-lhes atribuída pelos outros. Desta forma, acontecimentos completamente irrelevantes podem romper uma convenção. Os exemplos nos mercados financeiros são abundantes. Igualmente abundantes são os exemplos quer no domínio dos fins, quer no das obrigações: a exibição mediática de um exemplar pode deslocar a orientação de multidões, assim como a divulgação de um caso saliente de fraude fiscal pode "justificar" a fuga fiscal de milhões (Gintis et al., 2005). 


\subsection{A armadilha da liquidez}

As ordens convencionais são por natureza instáveis e estão permanentemente sujeitas ao colapso. A armadilha da liquidez representa em Keynes esse colapso - perdida a confiança nas convenções, os agentes refugiam-se no mais líquido dos activos. Generalizando, a armadilha da liquidez corresponde à ruptura dos compromissos seja qual for a forma que eles assumam; à desvinculação em massa e ao pânico.

O movimento de pânico decorrente da quebra de confiança assume em Bauman duas formas: a primeira é a não "aditividade" em causas comuns dos sofrimentos individuais; a segunda, a fuga - a procura de refúgio no interior de "bolhas" protegidas. As duas formas de Bauman têm em comum a recusa de "investimento" nas relações sociais ou na assunção de compromissos e obrigações de qualquer espécie.

A primeira forma da armadilha conduz Bauman à representação da modernidade líquida como uma sociedade desprovida de meios que lhe permitam actuar sobre a origem sistémica dos padecimentos individuais uma sociedade bloqueada.

A acção colectiva, como decorre de abundante investigação teórica e empírica sobre o tema (Ostrom, 1990; Gintis et al., 2005), depende crucialmente, entre outras condições, da perspectiva de continuação indefinida da interacção, sendo, portanto, incompatível com as relações na modernidade líquida, caracterizadas pela precariedade. Bauman está sobretudo preocupado com a impossibilidade da acção colectiva na esfera política. Existem, no entanto, outros domínios, incluindo os que mais respeito dizem ao leitor economista, em que esta implicação da liquidez se manifesta.

$\mathrm{Na}$ empresa e na organização modernas, a cooperação sempre foi um pré-requisito da produção tão importante como a divisão do trabalho, a monitorização e a coerção. As empresas e as organizações sempre reclamaram não só o corpo como a alma dos seus habitantes. Mas, enquanto a modernidade "sólida" confiava mais no controlo do corpo do que no da alma, a modernidade pós-panóptica necessita dos dois em igual proporção. Isso mesmo é patente na evolução das "ciências da gestão", que deixaram de ser simplesmente uma engenharia social para se transformarem numa engenharia dos espíritos envolvendo patéticos rituais de identificação, como os que actualmente são encenados nas empresas e noutras organizações.

Mas, nas condições da modernidade líquida, a lealdade - o atrito ao exit em Hirschman (1970) - é mais difícil de cultivar: concentrados na arte da fuga, os residentes estão mais preocupados com a aquisição de capacidades e com a realização de feitos que lhes facilitem o exit, ou que tornem a ameaça 
de exit mais credível, do que com a realização das tarefas que mais contribuem para a continuação do empreendimento colectivo.

Tal como na esfera política, também nas empresas e nas organizações pós-panópticas, a liquidez pode dissolver os fundamentos da acção colectiva.

A segunda forma da armadilha em Bauman é o movimento de pânico em direcção ao refúgio muralhado do lar ou da "comunidade"; uma fuga por saídas de emergência que não é desordenada, no sentido em que cada um se precipita para a porta que parece ser escolhida pelos seus semelhantes, para se encontrar do outro lado no interior de uma aglomeração de semelhantes, unidos pelo medo do exterior, mas no resto tão separados como dantes. $\mathrm{Na}$ medida em que o resultado, eventualmente não intencional, deste movimento é a segregação (Schelling, 1978), a sociedade fracturada que resulta do exit colectivo é ainda mais perigosa do que aquela que justificou a fuga. Bauman ilustra este processo com o caso dos condomínios fechados e outras áreas residenciais segregadas nas cidades da modernidade líquida. No entanto, algo semelhante poderá ocorrer com a fragmentação dos serviços públicos de saúde e de ensino em consequência do exit das classes média e alta.

É difícil conceber a coabitação humana numa ordem meramente convencional; tanto mais que os contratos - o instrumento institucional que se apresenta como cimento da modernidade líquida - dependem muito mais do que geralmente se supõe de um conjunto de valores e de obrigações normativas institucionalizadas.

$\mathrm{Na}$ medida em que todos os contratos são incompletos, embora em grau variável, a viabilidade dos laços contratuais depende sempre do elemento não contratual que eles necessariamente envolvem - a obrigação normativa de respeitar as promessas. O fundamento da obrigação normativa, como é sabido, tanto pode ser a prudência como a honestidade. O problema é que a liquidez não parece ser o caldo de cultura apropriado para qualquer uma destas virtudes, já que tanto a prudência como a honestidade pressupõem contextos relacionais estáveis e continuados.

A eficácia do contrato depende de "alguma coisa" mais do que da sua especificação, da monitorização e da ameaça de sanções. Arrow chamava confiança a essa alguma coisa. O problema é que a confiança, como avisadamente recordava Arrow, faz parte do rol de bens que o dinheiro não pode comprar: "se temos de a comprar é porque temos dúvidas acerca do que compramos" (Arrow, 1974: 23).

\section{Notas conclusivas}

À luz da análise precedente, a modernidade líquida - a sociedade desprovida de referenciais normativos e valores suficientemente partilhados, uma 
ordem meramente convencional - surge como uma impossibilidade; uma utopia (ou uma distopia) irrealizável. A arte da fuga, quando praticada por todos em simultâneo, destrói-se a si mesma, transformando-se em armadilha - uma fuga generalizada que inviabiliza o estabelecimento de quaisquer compromissos ou laços duradouros, incluindo aqueles que a própria modernidade líquida, baseada em contratos, pressupõe. Mas, na medida em que podem existir, e manifestamente existem, tentativas de realizar a utopia da liquidez, vale a pena procurar descortinar os futuros que daí decorrem.

A análise de Bauman, à semelhança da de Polanyi (1944), sugere que o movimento no sentido da liquefacção (ou da realização da sociedade de mercado) desencadeia necessariamente um contra-movimento. Esse contra-movimento, no entanto, é politicamente indeterminado - pode dar origem a diferentes cenários. Bauman aponta para dois cenários tendenciais distintos, mas relacionados, e um contra-cenário contrastado.

O primeiro cenário, inspirado na análise de Erich Fromm, antevê que

quando "cada indivíduo deve ir em frente e tentar a sua sorte", quando "tem de nadar ou afogar-se”, "a busca compulsiva de certeza” é desencadeada e a procura desesperada de "soluções" capazes de "eliminar a consciência da dúvida" começa; então, tudo o que prometa "assumir a responsabilidade pela certeza" é bem vindo. (Bauman, 2000: 20)

$\mathrm{Na}$ medida em que os governos, "tornados impotentes para agir quanto às raízes da insegurança existencial e da ansiedade dos sujeitos" (Bauman, 2000: 109), podem sentir-se tentados a prover segurança - se bem que na forma de produtos derivados, orientados para a salvaguarda do corpo e da propriedade -, a "busca compulsiva de certeza" pode degenerar em paroxismos securitários.

O segundo cenário de Bauman, o da fuga para a comunidade, conduz à guetização. Este quadro, complementado com um esvaziamento das funções de soberania do Estado que fosse ao ponto da sua perda do monopólio da coerção, traduzir-se-ia numa transferência da violência do nível do Estado para o nível neo-tribal das comunidades.

Recusando-se a admitir a possibilidade de uma qualquer reinserção comunitária, Bauman investe a esperança num contra-cenário em que a ordem social é construída "por confrontação, debate, negociação e compromisso entre valores, preferências, modos de vida escolhidos e auto-identificações de muitos, mas sempre auto-determinados, membros da polis" (Bauman, 2000: 178). O que propõe é o "modelo republicano de unidade", o único que considera compatível com "as condições da modernidade líquida". 
O problema é fazer com que a mesma modernidade que levou "à corrosão e lenta desintegração da cidadania" (Bauman, 2000: 36) evolua no sentido desta unidade na diferença. Não sabemos como, nem se é possível. Como Bauman, podemos apenas prevenir e esperar que o diagnóstico, ao descortinar o nexo perdido entre condições objectivas e experiências subjectivas, contribua para "desocultar a possibilidade de viver em conjunto de uma outra forma" (Bauman, 2000: 215) e despertar o desejo de o conseguir.

\section{Referências bibliográficas}

Arrow, Kenneth (1974), The Limits of Organizations. New York: Norton.

Bauman, Zygmunt (2000), Liquid Modernity. Cambridge: Polity Press.

Bauman, Zygmunt (2001), Community: Seeking Safety in an Insecure World. Cambridge: Polity Press.

Beckert, Jens (1996), "What is Sociological about Economic Sociology? Uncertainty and the Embeddedness of Economic Action", Theory and Society, 25, 803-840.

Dupuis, Jean-Pierre (1992), Le sacrifice et l'envie: Le liberalisme aux prises avec la justice sociale. Paris: Calman-Lévi.

Gintis, Herbert et al. (orgs.) (2005), Moral Sentiments and Material Interests: The Foundations of Cooperation in Economic Life. Cambridge MA: The MIT Press.

Hirschman, Albert (1970), Exit, Voice and Loyalty: Responses to Decline in Firms, Organizations, and States. Cambridge MA: Harvard UP.

Hirschman, Albert (1982), "Rival Interpretations of Market Society: Civilizing, Destructive, or Feeble?", Journal of Economic Literature, 20, 1463-1484.

Keynes, John M. (1936), The General Theory of Employment, Interest and Money. London: MacMillan.

Marx, Karl; Engels, Friedrich (1848), Manifesto of the Communist Party. Disponível em www.marxists.org/archive/marx/works/1848/communist-manifesto/index.htm.

Orléan, André (1999), Le pouvoir de la finance. Paris: Odile Jacob.

Ostrom, Elinor (1990), Governing the Commons: The Evolution of Institutions for Collective Action. Cambridge: Cambridge UP.

Polanyi, Karl (1944), The Great Transformation: The Political and Economic Origins of Our Time. Boston: Beacon Press.

Rodrigues, João (2007), "Liquidez, especulação e convenções - Uma análise a partir de Keynes", mimeo.

Runde, Jochen (1991), "Keynesian Uncertainty and the Instability of Beliefs", Review of Political Economy, 3(2), 125-145.

Schelling, Thomas C. (1978), Micromotives and Macrobehavior. New York: Norton and Company. 